\title{
Effect of Surface Modification on Candidate Alloys for Canadian SCWR Fuel Cladding
}

\author{
Jian Li1, Pei Liu', Renata Zavadil1, Tom Malis', Sami Penttilä2 \\ ${ }^{1}$ CanmetMATERIALS, Hamilton, Canada \\ ${ }^{2}$ VTT Technical Research Centre of Finland, Materials for Power Engineering, Espoo, Finland \\ Email: Jian.Li@NRCan-RNCan.gc.ca
}

Received 26 November 2013; revised 7 January 2014; accepted 17 January 2014

Copyright (C) 2014 by authors and Scientific Research Publishing Inc.

This work is licensed under the Creative Commons Attribution International License (CC BY). http://creativecommons.org/licenses/by/4.0/

(c) (i) Open Access

\begin{abstract}
The Canadian Generation-IV supercritical water reactor (SCWR) requires peak cladding surface temperature of $800^{\circ} \mathrm{C}$ for a core outlet temperature of $625^{\circ} \mathrm{C}$. Materials selection for high temperature fuel cladding is becoming one of the major challenging tasks. Austenitic stainless steels with excellent corrosion resistance are often susceptible to stress corrosion cracking upon SCW exposure. Low-Cr steels such as $\mathrm{P91}$ exhibit good high-temperature mechanical properties, but the lack of sufficient $\mathrm{Cr}$ content makes this group of alloys corrode too fast. One possible solution is to use coatings or surface modification techniques to improve the surface resistance to corrosion. In this study, we investigated the effect of surface modification on commercial 316L stainless steel. Surface modification by mechanical deformation has marked improvement in corrosion resistance during SCW exposure. Possible mechanisms for such improvement are discussed.
\end{abstract}

\section{Keywords}

SCW; Surface Modification; FIB

\section{Introduction}

The Canadian SCWR Concept will operate at a core outlet temperature of $625^{\circ} \mathrm{C}$ and $25 \mathrm{MPa}$ of pressure. To achieve this, the peak cladding temperature can be as high as $800^{\circ} \mathrm{C}$. Cladding components are designed to be thin in order to improve neutron efficiency. High-temperature corrosion resistance in supercritical fluid is one of the key design requirements for in-core and out-of-core components. Corrosion resistance of commonly recognized alloy groups including Ni-based super alloys, austenitic stainless steels and ferritic/martensitic (F/M) steels was summarized by Allen et al. [1]. In general, F/M steels develop a thick but mechanically stable oxide layer, while austenitic stainless steels develop thinner oxide layer. Ni-based alloys appear to form very thin sur- 
face oxide, however pitting was observed in the vicinity of intermetallic precipitates [2]-[5]. Besides wall thinning, corrosion could also result in alloying element release into SCW fluid that poses significant threats to downstream piping and turbine blades [6]. The fact that most of austenitic stainless steels with high-Cr contents are susceptible to intergranular attack and stress corrosion cracking (SCC) makes the cladding selection a challenging task (Mitton et al. [7]). Kaneda et al. [8] reported that $\mathrm{Zr}$ modified stainless steel with ultra-fine grained microstructure not only provided better corrosion resistance, but also showed no sign of SCC in their slow-strain rate test under SCW condition. However, materials with fine-grained microstructure tend to have poor hightemperature creep resistance due to grain boundary sliding.

High-temperature cladding requirements include high-temperature mechanical strength, creep resistance, corrosion resistance, SCC resistance and irradiation damage. Corrosion resistance is mostly governed by alloy's $\mathrm{Cr}$ content. Based on current knowledge, a minimum of $20 \mathrm{wt} \% \mathrm{Cr}$ content is needed for adequate SCW corrosion resistance. Stainless steels with more than $20 \% \mathrm{Cr}$ will fall into two categories-ferritic (with no or small $\mathrm{Ni}$ content) or austenitic (with high Ni content). For Canadian SCWR fuel cladding, most ferritic stainless steels do not meet the minimum strength requirement at designed temperature. Some austenitic steels meet the strength requirement and have acceptable corrosion resistance. However, they are generally prone to SCC. Based on the study by Keneda et al. [8], it is possible to improve the SCC resistance by refining grain size near the cladding surface. In this study, austenitic stainless steel 316L samples with two different surface finishes are tested in order to understand the effect of cold work near the sample surface on corrosion resistance.

\section{Experimental}

To study the effect of subsurface microstructure evolution at reactor operating temperature, a stainless steel $310 \mathrm{~S}$ coupon with machine surface condition was subjected to thermal anneal at $650^{\circ} \mathrm{C}$ for 100 hours followed by $850^{\circ} \mathrm{C}$ for 24 hour in a tube furnace protected by Argon. Subsurface microstructure evolution was studied using Focused Ion Beam (FIB) cross sectioning and imaging technique.

Stainless steel 316L has been extensively used in current light water reactors (LWR). The nominal chemical composition of this alloy is shown in Table 1. Corrosion rate of SS316L is generally high under high temperature SCW exposure. In this study, 316L was selected in order to show the effect of surface conditions to their corrosion resistance.

Two AISI 316L specimens were prepared from a $\phi 10 \mathrm{~mm}$ tube piping of VTT Technical Research Centre test loops. The wall thickness of the tube samples was $1.5 \mathrm{~mm}$. The length of the samples was approximately $10 \mathrm{~mm}$. One of the samples had machined surface finish, and the other sample was polished to obtain 600-grit surface finish. Both specimens were exposed to SCW at $650^{\circ} \mathrm{C}$ at $25 \mathrm{MPa}$ for 1000 hours in an autoclave connected to a recirculation water loop at VTT Technical Research Centre. The tube samples were attached to a specimen holder, and electrically insulated from the rack and the autoclave body. After the test, metallographic samples were prepared, and oxide layer structures were studied from the cross-sections prepared using the FIB microscope.

\section{Results}

\subsection{Thermal Anneal and Subsurface Microstructure Evolution}

The sample with machined surface suffers from subsurface mechanical damage. This damaged zone contains heavily deformed microstructure and shear bands. The depth of the deformed zone depends on machining process and materials properties. Such shallow deformation zone is very difficult to be captured by conventional metallographic cross-sectioning, and Scanning Electron Microscope (SEM) examinations do not provide enough contrast to characterize this relatively shallow deformation zone. The samples were cross-sectioned using a high-resolution FIB, and secondary electron images shown in Figure 1 depict the evolution of deformed subsurface microstructure of stainless steel 310S after various thermal anneals. Details of the FIB imaging technique and its advantages were described in literatures [9] [10].

Table 1. Chemical composition of the 316L stainless steel (wt\%).

\begin{tabular}{ccccccccc}
\hline $\mathrm{C}$ & $\mathrm{Si}$ & $\mathrm{Mn}$ & $\mathrm{S}$ & $\mathrm{P}$ & $\mathrm{Cr}$ & $\mathrm{Ni}$ & Mo & $\mathrm{Fe}$ \\
\hline 0.017 & 0.36 & 1.72 & 0.01 & 0.028 & 17.29 & 13.13 & 2.52 & balance \\
\hline
\end{tabular}



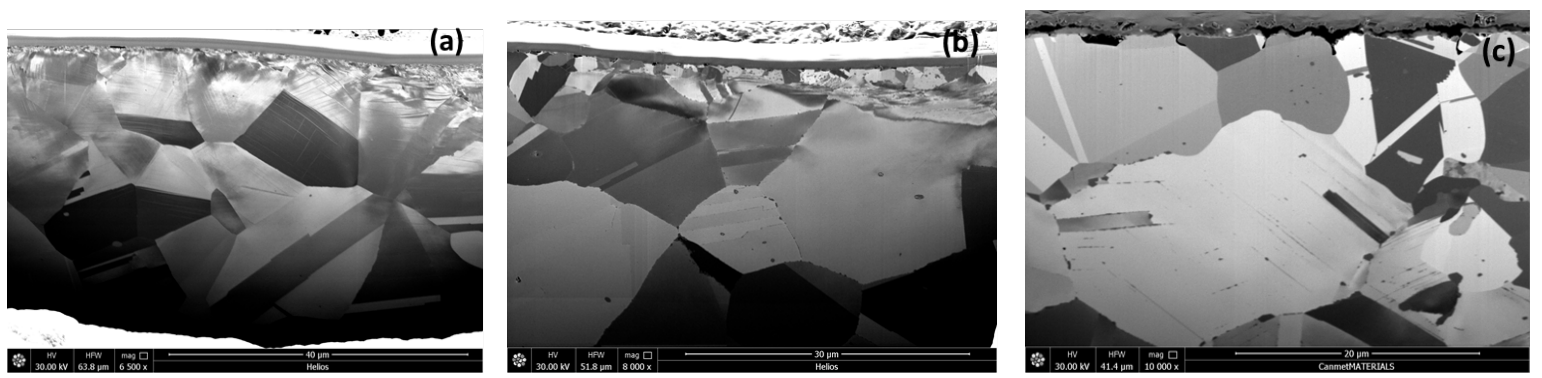

Figure 1. High-resolution FIB images 310S. (a) As-deformed; (b) Annealed at $650^{\circ} \mathrm{C}$ for 100 hours; (c) Annealed at $850^{\circ} \mathrm{C}$ for 24 hour.

The material immediately beneath the top surface of the machined sample was highly deformed. This layer was very thin (on the order of $1-2 \mu \mathrm{m}$ in this case). This deformed layer would have enough stored strain energy to recrystallize at relatively low temperature during SCW exposure. Shear bands were found immediately beneath the heavily deformed layer. Upon annealing at $650^{\circ} \mathrm{C}$ for 100 hours, the severely deformed subsurface layer was recrystallized and formed a thin layer with fine grained microstructure. This fine grained region was replaced by large grained microstructure after the short heat treatment at $850^{\circ} \mathrm{C}$ (Figure 1(c)).

\subsection{Effect of Surface Modification on the Corrosion Resistance in SCW}

The two 316L stainless steels coupons were prepared with different surface conditions, and SCW corrosion experiment resulted in significantly different weight changes [11]. The coupon with machined surface was found to have little weight change. SEM images in Figure 2 show that after SCW exposure for 1000 hours, the machined surface was seen to be smooth with occasional large surface oxide crystals (Figure 2(a)), while the initially polished surface (600-grit) was covered by a thick oxide layer (Figure 2(b)).

FIB cross-sections of these two samples (Figure 3) showed distinct different corrosion products. The originally machined surface formed a very thin surface oxide layer, and immediately beneath it was a layer that composed of fully recrystallized sub-micrometer sized grains. The specimen with an initially polished surface (600-grit) formed a thick surface oxide layer composed of iron oxide. The severe oxidation was further confirmed by our Transmission Electron Microscopy (TEM) analysis. Internal oxidation also occurred beneath the oxide layer of the 600-grit polished specimen, and extend deep into the substrate. The oxidation of substrate materials was associated with the formation of voids at grain boundaries and severely oxidized grain interiors.

\section{Discussion}

The machined surface exhibited significant residual strain near the top surface depicted as a layer of mottled microstructure in Figure 1(a). SCW exposure at $650^{\circ} \mathrm{C}$ recrystallized this heavily deformed layer forming a finegrained microstructure near the surface (Figure 3(a)). Such recrystallization process is simulated by heat treatment experiment at the same temperature as shown in Figure 1(b). Below this recrystallized layer, the residual strain as represented by shear bands is not sufficient for recrystallization to occur at this temperature. The abundant grain boundaries in the fine-grained layer can act as short circuits for outward diffusion of $\mathrm{Cr}$ from the bulk during SCW experiment. This helps to provide enhanced level of $\mathrm{Cr}$ at the surface to maintain a continuous $\mathrm{Cr}_{2} \mathrm{O}_{3}$ passive layer during SCW exposure. The high dislocation density within the deformed layer beneath the fine recrystallized grains also facilitates $\mathrm{Cr}$ outwards diffusion. The dense and continuous $\mathrm{Cr}_{2} \mathrm{O}_{3}$ film, once formed on the surface, also reduces inward diffusion of oxygen. It is expected that this fine grained layer also provides extra strength to the cladding surface, and improve its SCC resistance.

Tsuchiya et al. [12] reported a comparative study of corrosion and SCC properties of normal-size and finegrain 304L, 316L and 310S stainless steels in SCW at $550^{\circ} \mathrm{C}$ containing $8 \mathrm{ppm}$ oxygen. In their 6-week SCW corrosion tests, the corrosion rate of fine-grain alloys was found to be less than $0.005 \mathrm{~mm} /$ per year (with the $310 \mathrm{~S}$ alloy showing a corrosion rate of only $0.00017 \mathrm{~mm} / \mathrm{year}$ ) while the alloys with normal grain size (>25 microns) showed a corrosion rate generally greater than $0.01 \mathrm{~mm} /$ year. Auger Electron Spectroscopy (AES) analysis showed a higher level of $\mathrm{Cr}$ in the oxide formed on the fine-grain samples than that in the normal microstructure. 

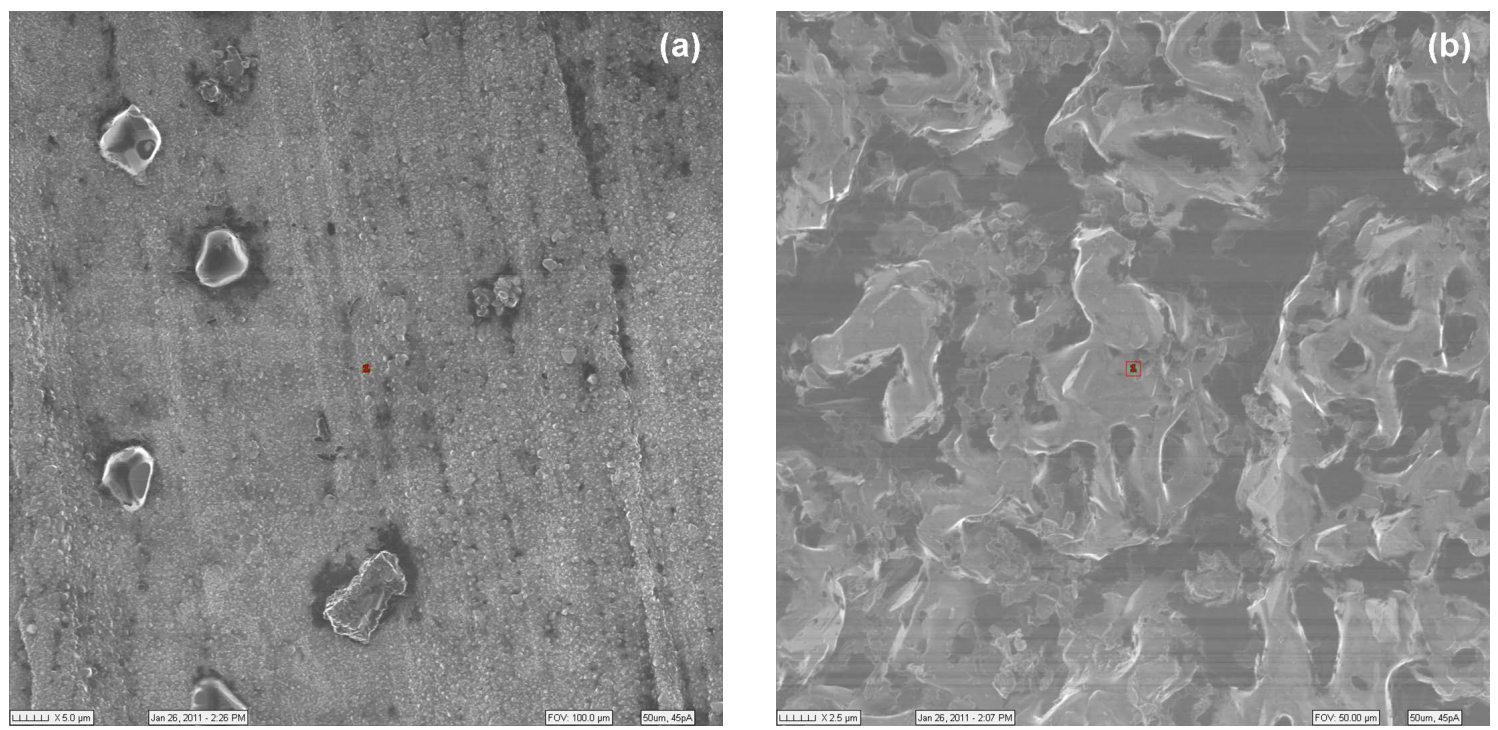

Figure 2. SEM images of surface morphology after SCW exposure. (a) Machined surface; (b) \#600 grit polished.
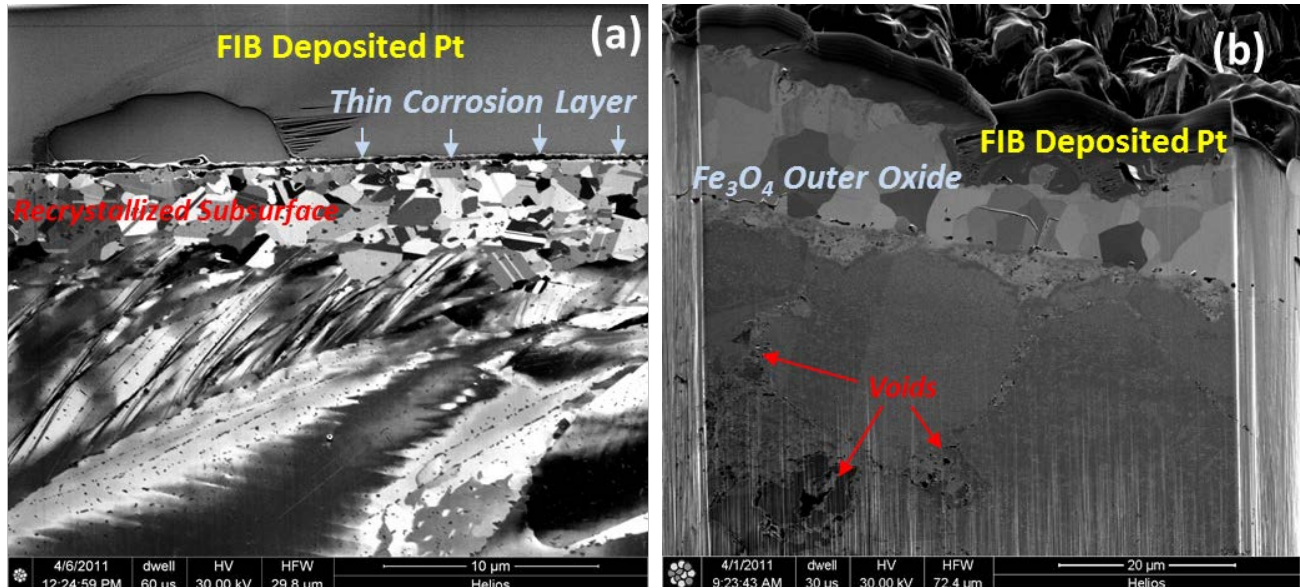

Figure 3. FIB cross section of the SCW tested 316L samples. (a) Machined surface; (b) 600-grit polished.

The polished 316L would have this deformed layer removed prior to SCW exposure. The large grained structure is oxidized much faster. The rate of corrosion (oxidation) is affected by both the outward diffusion of Fe to form $\mathrm{Fe}_{3} \mathrm{O}_{4}$ crystals on the surface, and inward diffusion of oxygen to form the internal Cr-rich complex oxide. Because of the reduced number of grain-boundaries that are "short-cut" pathways for $\mathrm{Cr}$ diffusion, the integrity of highly protective chromium oxide could be compromised at the initial stage of SCW exposure due to inefficient Cr supply.

Similar finding of void formation beneath the metal/oxide interface was reported in other studies of nickel based alloys exposed to high-temperature steam. It has been suggested that the oxidation of Mo-rich particles and subsequent evaporation of Mo oxides is the cause of such void formation in Alloy 625. In austenitic stainless steels tested in SCW, there have been no reports to date of void formation in the interior of the subsurface microstructure. If this is confirmed as a generic degradation problem for 3xx series stainless steels, its implication to Canadian SCWR fuel cladding selection is significant. This is because voids formation can seriously reduce cladding strength. They can also serve as initiation sites for internal cracks that lead to SCC.

Ideally, the residual strain generated by surface machining process should be just enough for this subsurface layer to dynamically recrystallize at the initial stage of SCW exposure. Too much residual strain or too high of SCW exposure temperature could result in grain growth, and diminish such benefit that not leads to accelerated 
corrosion, but also compromises SCC resistance.

Maekawa et al. [13] reported a clear difference in corrosion behaviour between electropolished, pickled, or abraded (400 grit abrasive paper) samples. They found the corrosion resistance was different above and below the critical point. Ruther et al. [14] reported that in SCW, surface preparations that gave a strain-free surface resulted in maximum general corrosion while the surface finishes that resulted in severe cold-work reduced general corrosion. This agrees with the findings in this current study. In another study, Ziemniak et al. [15] investigated the effect of electropolishing on the corrosion of stainless steel 304 under subcritical condition and reported that in a hydrothermal environment surface treatments that reduce cold work are very effective in reducing the general corrosion rate. Therefore, components at the core inlet and outlet may need different type of surface treatments.

\section{Conclusion}

Certain surface modification can improve corrosion resistance of stainless steels significantly, as seen in the 316L samples that were tested in both machined and polished surface finishes. The machining introduced significant sub-surface plastic deformation, which led to recrystallization and grain-refining. There was much less oxide formed on the machined sample than that on the polished samples. The mechanism for improved corrosion resistance is considered to be associated with enhanced diffusion of $\mathrm{Cr}$ to the metal surface through grain-boundaries.

\section{Acknowledgements}

The authors would like to thank financial support from PERD and from NSERC/NRCan/AECL Generation IV Technologies Program.

\section{References}

[1] Allen, T.R., Sridharan, K., Chen, Y., Tan, L., Ren, X. and Druizenga, A. (2008) Materials Development and Selection for Corrosion Resistance: A Critical Issue in Supercritical Water Reactors. 16th Pacific Basin Nuclear Conference, Aomori, 13-18 October 2008, Paper ID: P16P1032.

[2] Hong, G.T., Ordway, D.W. and Ziberstein, V.A. (1995) Materials Testing in Supercritical Water Oxidation Systems. First International Workshop on Supercritical Water Oxidation, Jacksonville, 6-9 February 1995.

[3] Kritzer, P., Boukis, N. and Dinjus, E. (1998) Corrosion of Alloy 625 in Aqueous Solutions Containing Chloride and Oxygen.Corrosion 98, Paper No. 415, NACE, Houston.

[4] Kriksunov, L.B. and Macdonald, D.D. (1995) Corrosion in Supercritical Water Oxidation Systems: A Phenomenological Analysis. Journal of the Electrochemical Society, 142, 4069-4073. http://dx.doi.org/10.1149/1.2048464

[5] Huang, S., Daehling, K., Carleson, T.E., Abdel-latif, M., Taylor, P., Wai, C. and Propp, A. (1989) Electrochemical Measurements of Corrosion of Iron Alloys in Supercritical Water. Supercritical Fluid Science and Technology, ACS Symposium Series 406, ACS, Washington DC, 287.

[6] Li, J., Guzonas, D., Wills, J., Dole, H., Michael, J., Zheng, W., Woo, O.-T. and Cook, W. (2009) Property of Passive Films Form on Alloys Tested in SCW Water. $4^{\text {th }}$ International Symposium on Supercritical Water-Cooled Reactors, Heidelberg, 8-11 March 2009, Paper \#56.

[7] Mitton, D.B., Eliaz, N., Cline, J.A. and Latanision, R.M. (2001) Corrosion 2001, Paper No. 01352, NACE, Houston.

[8] Kaneda, J., Kasahara, S., Kano, F., Saito, N., Shikama, T. and Matsui, M. (2011) Material Development for Supercritical Water-Cooled Reactor. $5^{\text {th }}$ International Conference on SCWR (ISSCWR-5), Vancouver, 13-16 March 2011.

[9] Li, J. (2006) Focused Ion Beam Microscope. Journal of Metal, 58, 27-31.

[10] Li, J. (2008) The Detection of Local Plastic Strain in Microscopic Scale. Materials Letters, 62, 804-807. http://dx.doi.org/10.1016/j.matlet.2007.06.065

[11] Penttilä, S. Horvath, A., Toivonen, A. and Zolnai, Z. (2011) Effect of Surface Modification on the Corrosion Resistivity in Supercritical Water. $5^{\text {th }}$ International Symposium on Supercritical Water-cooled Reactors (ISSCWR-5), Vancouver, 13-16 March 2011.

[12] Tsuchiya, Y., Kano, F., Saito, N., Ookawa, M., Kaneda, J. and Hara, N. (2007) Corrosion and SCC Properties of Fine Grain Stainless Steel in Subcritical and Supercritical Pure Water. CORROSION 2007, Nashville, 11-15 March 2007, Paper 07415. 
[13] Ruther, W.E., Schlueter, R.R., Lee, R.H. and Hart, R.K. (1965) Corrosion Behavior of Steels and Nickel Alloys in Superheated Steam. In: NACE-International Corrosion Conference Series.

[14] Maekawa, T., Kagawa, M. and Nakajima, N. (1968) Corrosion Behaviors of Stainless Steel in High-Temperature Water and Superheated Steam. Transactions of the Japan Institute of Metals, 9, 130-136.

[15] Ziemniak, S.E., Guilmette, P.A., Turcotte, R.A. and Tunison, H.M. (2008) Oxidative Dissolution of Nickel Metal in Hydrogenated Hydrothermal Solutions. Corrosion Science, 50, 449-462. http://dx.doi.org/10.1016/j.corsci.2007.07.013 